\title{
Architectural Research in the Use of Foam Plastics
}

\author{
Stephen C. A. Paraskevopoulos \\ Professor of Architecture \\ Architectural Research Laboratory \\ The University of Michigan \\ Ann Arbor, Michigan
}

\begin{abstract}
This program of research is being sponsored by the Agency for International Development of the U. S. Department of State in the interest of exploring the possibility of using foam plastics as a basic structural material for application in underdeveloped areas of the world. The preliminary investigation included a study of the mechanical properties of cellular plastics, methods for producing such materials (alone or in combination with other materials), as well as erection techniques which could result from the use of these materials. On the basis of this investigation certain conclusions were reached as to the kinds of structures which would make logical use of foam plastics, utilizing their unique properties and designing around their shortcomings.
\end{abstract}

\section{Research Objectives}

he program of research on foam plastics conducted at the University of Michigan which is sponsored by the Agency for International Development of the United States Department of State, is aimed at exploring the feasibility of using these materials for housing in underdeveloped areas of the world (1).

This article presents certain aspects of the research program which followed the feasibility study. The task at present is to investigate the potentials of foam plastics as a structural material. Our approach to structure has been molded by this objective, to wit, the extent to which foam plastics can contribute to the resolution of the housing problem in underdeveloped areas. This means that the ideal solution from the viewpoint of structural engineering may be far from being feasible for introduction in the less developed countries, not only because of cost, but also because of limitations in required production facilities and skills.

Although no specific country and no specific conditions have yet entered the picture, the fact that most developing nations are within a tropical or semi-tropical zone has been taken into consideration. In short, continuous exposure to high heat and humidity rather than extreme variations in temperatures may more often than not be the main problem. Also, resistance to high winds and impact from falling objects rather than long-term sustained loads may constitute the critical design factors.

It was decided quite early that we should avoid trying to design or develop a universal house. This, it was believed, would be a snare and a delusion. Plastics offer great versatility in both application and production. This advantage has been recognized in the production of other items, and should not be overlooked or wasted with respect to housing. The objective should always be to develop the proper total system (design, production, and marketing) and to make whatever adjustments may be needed within the system to enable it to cover the widest possible range of housing requirements in each developing country.

The selection of materials and systems in each case should be done by thorough survey and analysis. Conditions which may give the edge to $a$ material or a structural system in one country may be completely different or unsuitable in another. The materials and structural shapes that will ultimately prove best suited for a specific area will depend on a number of social, economic, technical, or environmental factors, even though the first selection may have to be decided only on the basis of presently available production facilities. Also, new breakthrough, in the technology of plastics (which can be anticipated) and the developments of new markets for a material (which would lower its cost) may completely reverse present day assumptions.

Consequently, we are investigating as wide a range of structures as possible within the limitations of time and resources. The four structures that have been selected for presentation illustrate the work presently under way. They include (example 1) the architectural application of a system already developed by a chemical company, (example 2) the development of a structure based on the properties of a composite material, (example 3) the application of a technique to a method for the erection of shelter, and (example 4) the investigation of a new idea for the erection of structural components. Other avenues of structural development have also been selected for further exploration. Of special interest are the possibilities offered for the production of structural components or total structures through vacuum-forming, filament-winding, and foam-inflating of tlexible membranes. 


\section{Approach to Structure}

To determine which structural systems are the most promising for further development, experimental structures have to be erected which make a logical use of the materials at hand. One cannot design intelligently with any material unless facts are available as to its properties, the shapes and sizes in which it can be obtained, and the possibilities of erecting the basic parts and assembling them into a final structure. More importantly, in order to establish a correlation between materials and structure, performance data must be obtained from actual application in the field. Creative design imagination is not stimulated by lack of familiarity with a material, and the plastics are not familiar materials in the same sense as concrete, brick, steel, lumber, and the other structural materials which architects and engineers have been using traditionally.

Before any meaningful design data can be developed, more research in the chemistry and production of these materials will be necessary to eliminate some of their present qualitative inconsistencies and to improve their overall performance. The low ultimate strength of low density plastics should not be allowed to inhibit their structural application. A material with inferior mechanical properties may turn out not to be difficult or impossible or uneconomical when properly used in structural design. It has to be kept in mind that the geometry of a structural section and the overall geometry of the total structure are major influencing factors. However, inconsistencies in the quality of certain foams, will have to be reduced to acceptable levels to avoid unpleasant surprises in construction.

In addition, more research is needed to determine more accurately the physical properties of foams and to what extent these can be improved through chemistry or better quality control. Especially, very little is known about the creep characteristics of cellular plastics. This phenomenon, also referred to as plastic flow, has presented us with some serious problems in certain instances, while in others it does not appear to be of any consequence. More information on this subject is needed, since even minor plastic deformations could lower the stability of a structure. This is particularly true in the case of fairly flat shells which can be very sensitive to changes in curvature caused by plastic deformations, as we have discovered in a recent experiment.

Through the erection of test structures and other experimentation with materials we have been trying to determine the influence of certain unknown factors in foam plastics on a structural form. This has been done in order to identify areas where additional research and development work is needed to improve performance standards. At the same time we are trying to establish the extent to which the present weaknesses and inconsistencies of the materials can be compensated through corrective measures within a structure.
To determine priorities in our structural research and development work, we have approached the problem from three directions. (1) Through the preliminary investigation of the mechanical properties of foam plastics, assumptions were drawn as to the kinds of structures which would be most logical from the structural engineer's point of view. (2) A similar investigation of production methods revealed the shapes and sizes as well as the kinds of structures (and structural components) that may most readily be obtained. (3) Finally, various possible erection techniques were suggested and these also limited the ways in which structures could be developed.

Without going into the details of structural analysis, if we accept the premise that certain problems related to the physical properties of foams can be resolved by industry and we turn our attention to basic mechanical properties, it becomes apparent that the fundamental limitation in structural design lies in the low modulus of elasticity of the plastic materials. The flexural stiffness of a structure will depend on the quantity EI, where $E$ is the modulus of elasticity and $I$ is the moment of inertia. The $\mathbf{E}$ value is an inherent property of the material. The I on the other hand does not depend on the material but on its distribution in the structure; in other words, on the structural geometry.

Since we must deal with relatively low $\mathbf{E}$ values, the only way we can eliminate excessive deformations is by increasing the structural stiffness through geometry. This will also lead to the reduction of stresses within the structure. Low stress values in the structure are essential not only because of the low material strengths, but also because creep seems to depend upon the stress level of the material.

It is apparent that the foam plastic structures which offer the largest potential are those in which stress levels are kept low by the distribution of loads throughout the structure, and where load and stress concentrations are avoided as much as possible. Therefore, the structural solutions we have sought have been within the family of "surface structures," especially shells and folded plates, which have such characteristics.

Through further analysis involving the basic families of internal stresses, theoretical solutions can be obtained which will be fairly ideal from a purely structural viewpoint. However, these solutions may be far from ideal with regard to application, especially so far as our particular project is concerned.

The possibilities and limitations imposed by presently available production methods are major factors influencing the structural solutions we are seeking. Such factors relate both to the form of the structure as well as to the form in which materials can be used. Finally, factors relating to the erection of a structure must also be considered, not only because of limitations which may be imposed, at least initially, by the lack of facilities and skills, but also because the nature of these materials 
presents some unique possibilities for the erection of structures which may affect considerably their cost in place.

The great advantage of plastics is that, as synthetics, they can be made according to a wide range of performance specifications. This in turn allows one either to start with a material and then develop a structure, or to start with a structural concept and then develop the necessary material. In either case, during this initial stage of research, a major objective should be to discover what new architectural solutions are being made possible through the introduction of these new materials.

The examples that follow illustrate structures in varying degrees of development. With the exception of the first example which is being tested for long-term performance, the structures have been erected for the primary purpose of obtaining information regarding their behavior. It is still too early to release the data which is continuously being collected through measurement and observation. This information is looked upon only as a guide to assist us in developing a second generntion of test structures freed from certain present shortcomings.

\section{Example 1: Erection of a Dome with Polystyrene Foam by the "Spiral Generation" Process}

The "Spiral Generation" process" was demonstrated to us by the Dow Chemical Company in the spring of 1963. The process involves the use of a specially designed machine which bends, places, and fastens boards of plastic foam together in a predetermined shape. A variety of shapes can be produced by programming the machine. The machine head is mounted on a boom which turns around on a pivot mechanism. As the generation process begins, foam board material is placed in the machine head which then forms and seals it, layer upon layer, into a rising structural spiral. This development truly constitutes a landmark in building technology, since it is the first system to produce an architectural structure totally by a machine.

After examining a number of experimental structures which had been erected on company grounds and discussing the data which had been obtained thus far, we suggested the design and erection of a building for public use. Our objective was to study and resolve various architectural detail problems, and to obtain data on actual costs, weathering properties of polystyrene foam bearing a light coating of paint, public acceptability, and most important, the effect of public use on the structure's durability.

A local golf club's need for a temporary club facility became the vehicle for a full-scale field test structure. The club provided the site and assumed responsibility for all construction with

\footnotetext{
* Invented by Donald $R$. Wright, an engineer in the longrange plastics application laboratory of the Dow Chemical Company. Until this system is more fully developed the company is carefully controlling its application.
}

the exception of the polystyrene shell. Dow contributed the materials crew for the latter. The structure, encompassing a dome 45 feet in diameter, was designed by our project staff to meet the program requirements.

In erecting this structure a one-foot wide by three-foot deep trench was first excavated corresponding to the diameter of the dome. The trench was bridged at intervals by $2 \times 4$ inch wood blocks which supported a base ring made from angle iron (Figure la). A starter strip of foam was then at. tached to the base ring and the spiral generation process began (Figure $1 b$ ). The dome, consisting of boards 4 inches thick with an approximate density of 2 pounds per cubic foot, was constructed in less than 12 hours by two men (Figure $1 c$ ).

Following its completion, the dome was lowered into the trench by approximately 30 students using ropes connected to the base ring (Figure $1 d$ ). After the dome had been lowered and the trench backfilled with earth (fully on the outside and partly on the inside), all openings were marked, cut and reinforced around the edges with fiberglass cloth and epoxy resin (Figures 1e, If and $1 g$ ). At the same time a few of the end joints between the foam plastics found to be still partly open were sealed with epoxy resin and ground glass. The floor slab was then poured and its edge was anchored to the dome.

The dome exterior was painted with a mixture of latex paint and vermiculite. This operation was accomplished in short order by simply bringing the paint from the inside to the top of the dome, letting it flow down on the exterior surface and distributing it evenly by rotating a squeegee (Figure $1 h$ ). Vermiculite was added to the latex paint in order to provide a fairly rough surface that would be somewhat unpleasant to the touch and thus discourage people from picking at the surface of the structure. One can call it a psychological coating. The interior surface was treated with a similar but somewhat heavier coating. Window glass for the exterior walls was cut and placed in wooden mullions. The joint between the dome and the glass was made watertight and flexible by using a polyethylene foam gasket made in our laboratory and bonded with contact cement to the dome's interior surface (Figures $1 i$ and $1 j$ ).

The structure has been under close observation for over a year now and has so far performed very well. A few small cracks occurred at the area of contact with two window mullions but these were easily repaired with epoxy resin. These cracks probably occurred because of the way the mullions had been installed. In general any damage to the dome's surface can be easily repaired.

Public reaction to the structure has been good. No one has felt that the building is too fragile or too experimental, or that it is a cheap substitute for conventional construction. There is no evidence of damage to the outside or inside coating of the structure. This is very encouraging,

\footnotetext{
"Styrofoam FR", paints, and various secondary materials.
} 


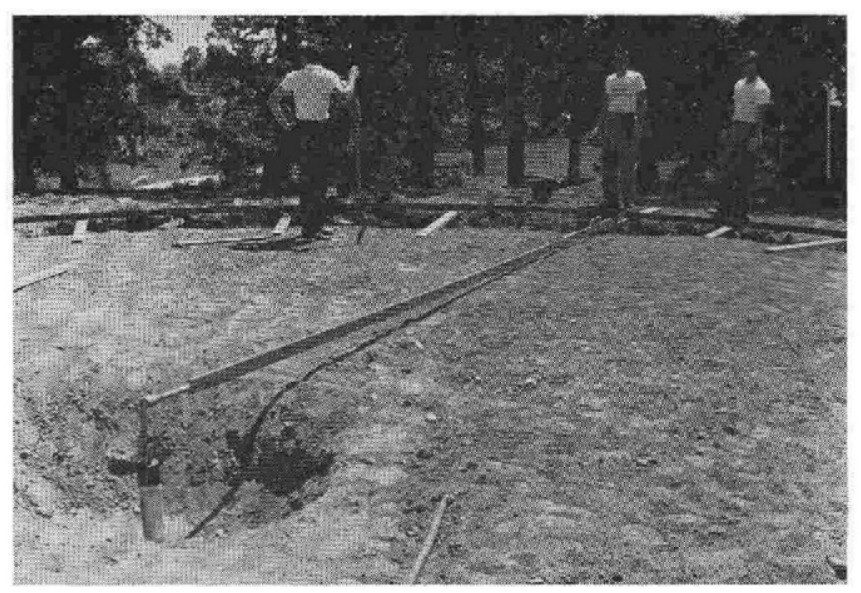

Figure 1A

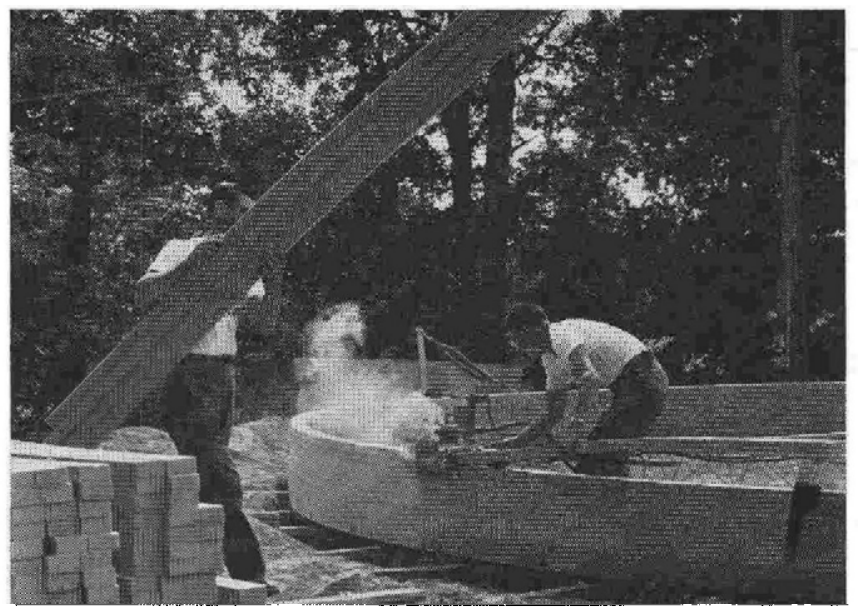

Figure 1B

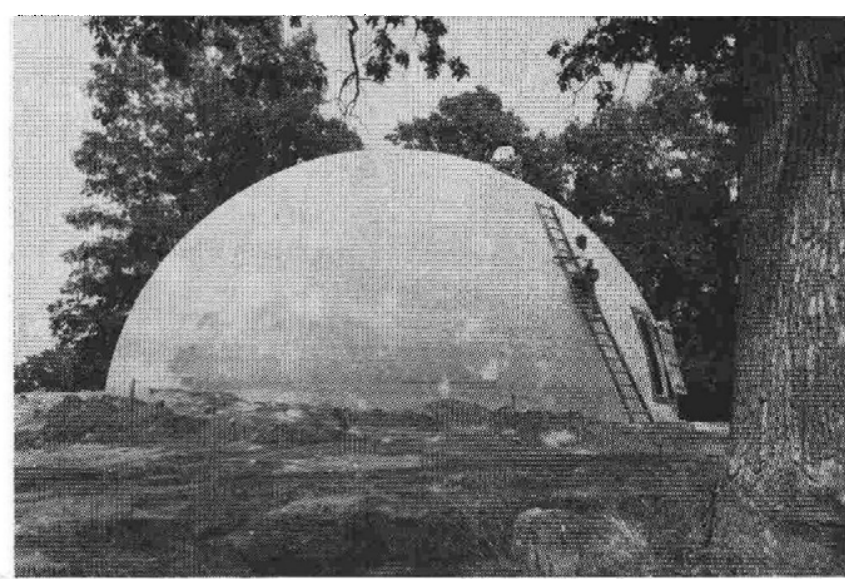

Figure 1C

since one of the things we hoped to learn was whether it was possible to protect a low-density foam structure by a coating of paint. Even though at times there have been over a hundred persons in the building, no one has tried to test it with fingernail, pocket knives and lighted cigarettes. The surface texture apparently serves to discourage such exploration.

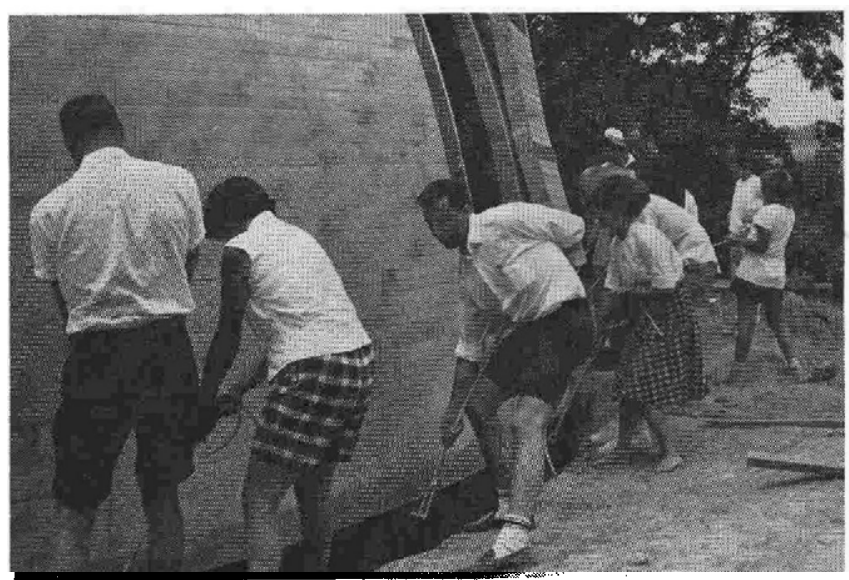

Figure 10

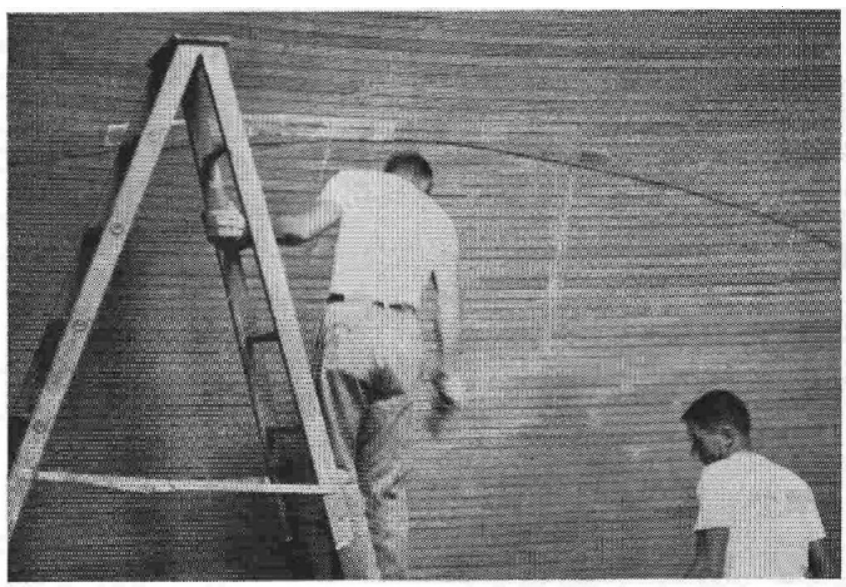

Figure 1E

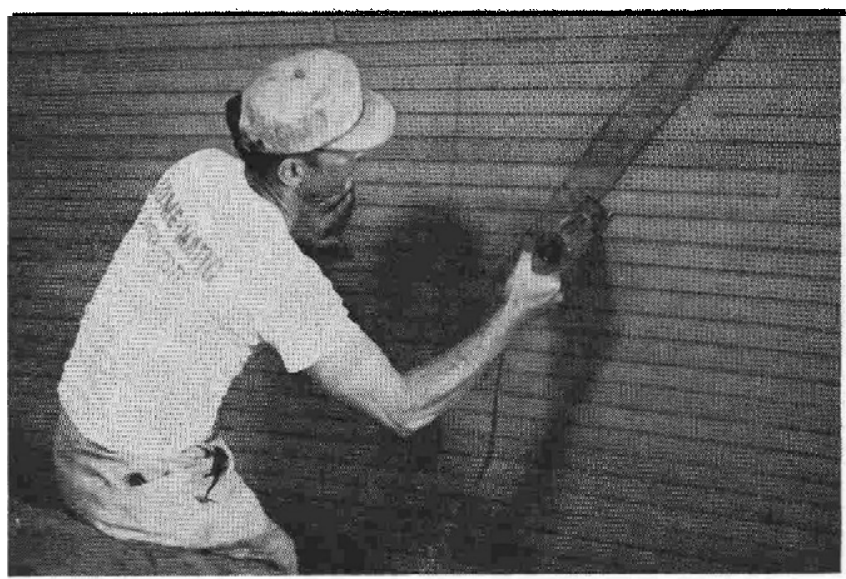

Figure 1F

It is apparent that the "Spiral Generation" process is unique, not only in concept but in its versatility. It derives its principal advantage from a well integrated use of a relatively simplified equipment and the economic use of materials. It affords a continuous system of rapid erection and is capable of producing structures which enjoy a high strength to weight ratio. 


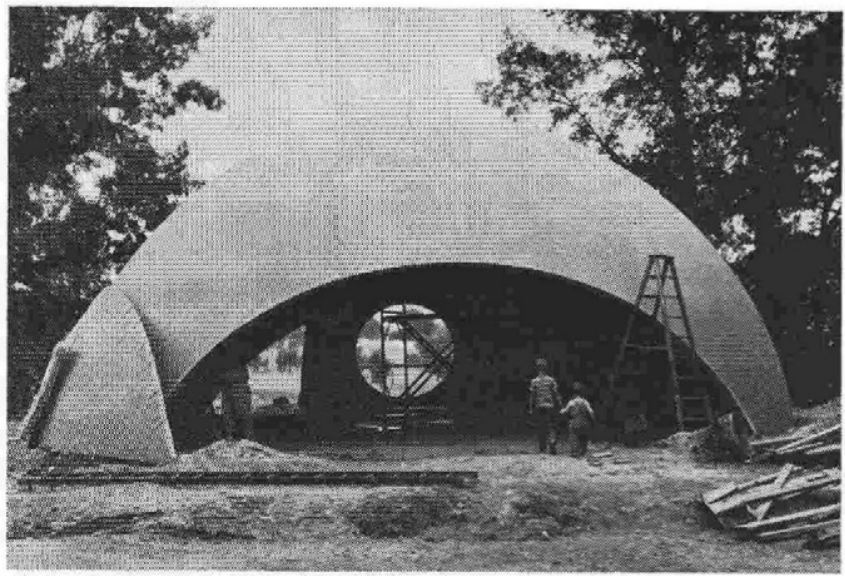

Figure $1 \mathrm{G}$

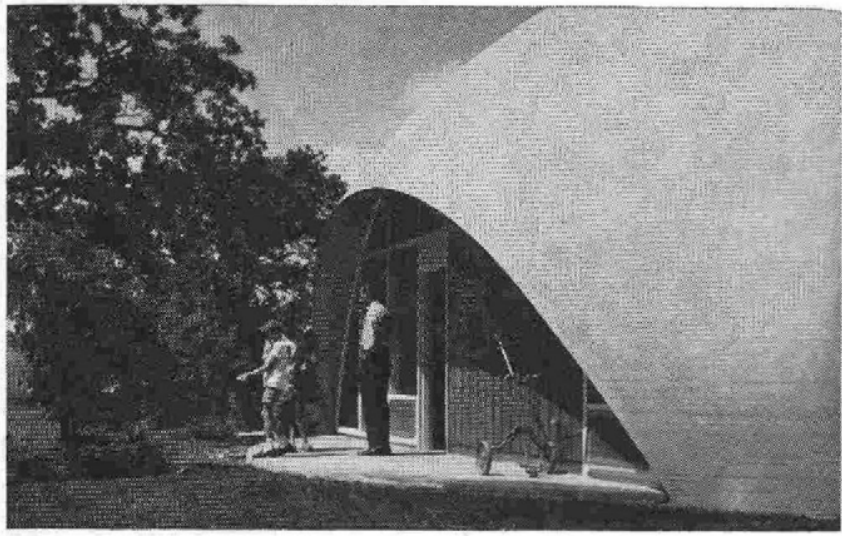

Figure 11

\section{Example 2: Development of Structures with Paper Skin Polyurethane Foam Panels}

In this case, the unique properties of the material and its method of production became the basis for the development of a structural system. The material is a urethane foam board surfaced on each side with kraft paper which can be coated with a variety of materials to meet structural and weathering requirements.

Today a number of companies are producing this material with some variation in the system of production. In general it is a continuous process in which the skins, introduced in rolls, go through a machine at the same rate as the foam that is being produced. The liquid foam components are uniformly distributed between the two skins. The unexpanded foam and skin sandwich moves through a form work or a dye where the foam expands. The material, after passing through a heat-curing operation, is cut to the desired length.

When the system and the material was first presented to us at the research center of Union Carbide Corporation, we became intrigued with its possibilities for use in folded plate construction. After initial investigation of the mechanical properties of the material with varying thicknesses of the foam core and a variety of skin coatings, it was decided to develop folded plate and curvilinear structural components which would utilize

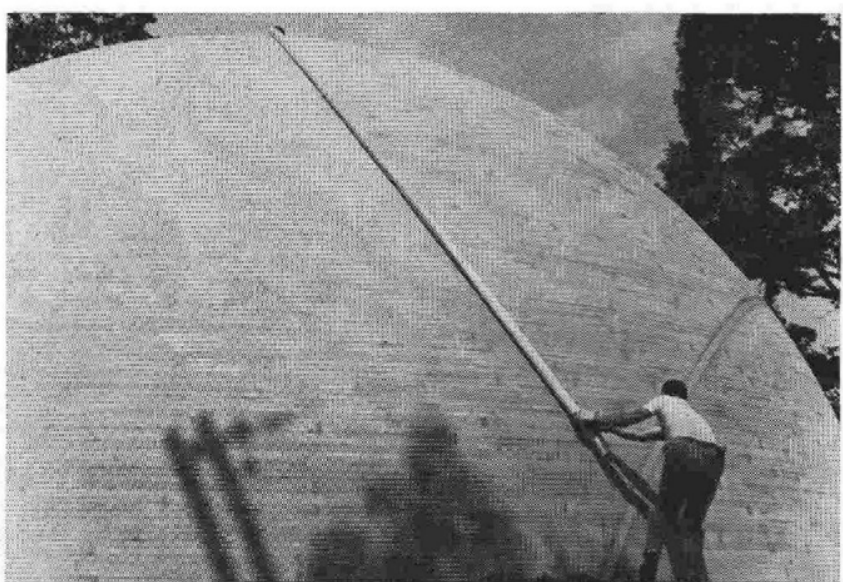

Figure 1H

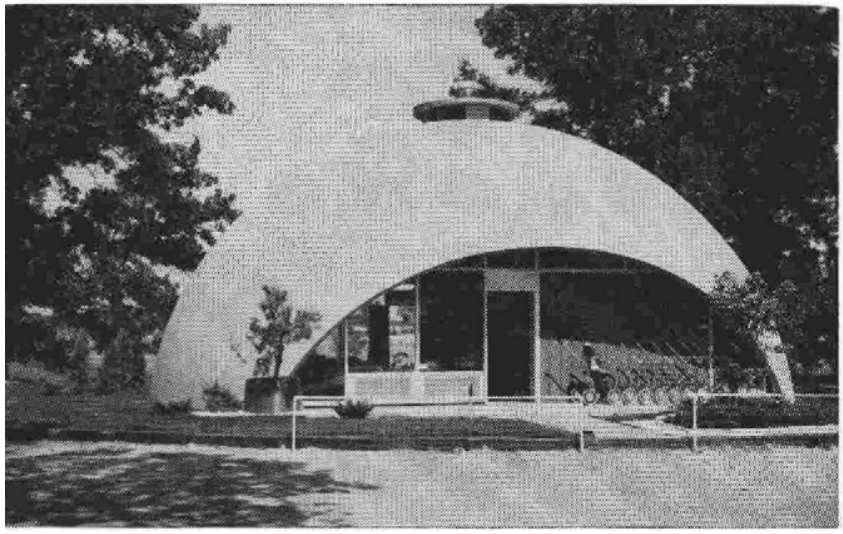

Figure 1J

the ease with which the material can be scored and bent, as a production factor determining the ultimate shape of the structure. Also it was thought desirable from a production standpoint that structural systems should be developed which could be produced adding equipment to the end of the line which produces the board.

With these ends in mind, three structural systems were developed ${ }^{*}$. One system takes the form of triangulated bents or components that can be prefabricated and field-assembled to create the floor, walls and roof of a building (Figure 2a). The second is similar in principle but resembles an airplane wing in its cross section, being made up of units that are shipped as flat sheets and then spread apart by the insertion of spreaders at the building site (Figure $2 b$ ). A third system utilizes simple semicircular sections that can be easily assembled in the field (Figure 2c).

Full-scale test bents of these three structures were constructed and tested. After preliminary testing it became apparent that the triangular cross section had the greatest potential since it could conceivably be used as a floor. This also suggested the possibility of a two-story structure being developed with a flat roof.

- Materials for this work and for the erection of the final test structure were produced by the Technifoam process and contributed to the project by Union Carbide. 


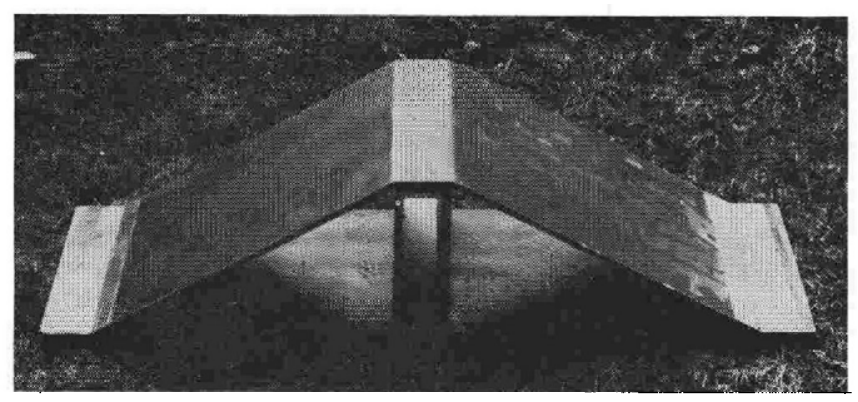

Figure 2A

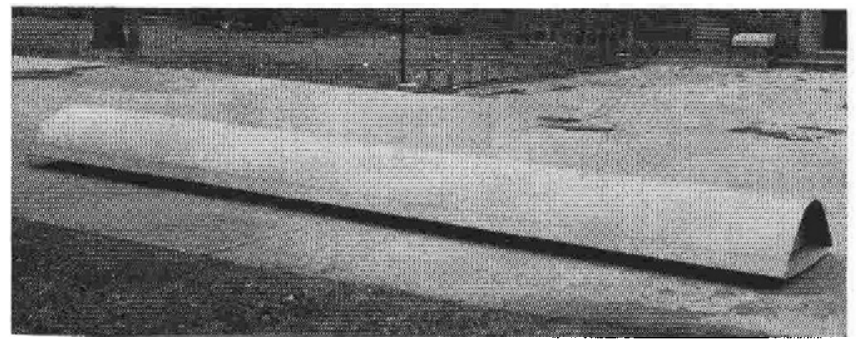

Figure 2C

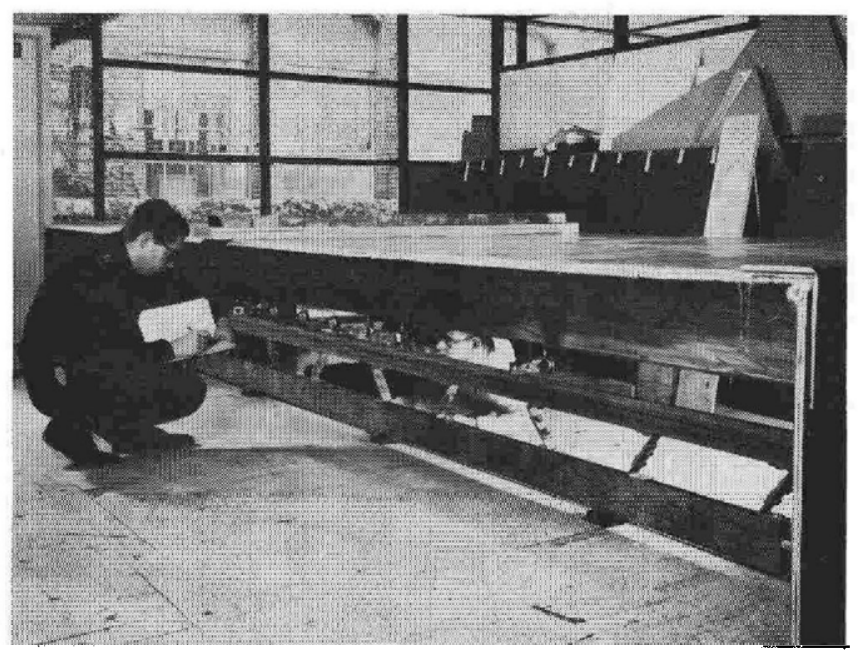

Figute 2E

Following initial study of a variety of cross sections which would produce adequate structural strength and rigidity, a test bent was constructed from urethane foam board $3 / 8$ " thick with an approximate foam density of 2.6 pounds per cubic foot. All paper surfaces of the board were impregnated with polyester resin . Polyester resin was also used in conjunction with fiberglass tape to join the various parts of the structure together. The bent is 16 feet long, 5 feet wide and 12 inches deep. The cross section is the same for the horizontal beam and the vertical supports (Figures $2 d$ and $2 \mathrm{e}$ ).

The test procedure was designed to accomplish three things: (1) to establish the capacity of the section within an arbitrary allowable deflection; (2) to provide accurate information on the elastic behavior of the structure; (3) to establish the pat-

\footnotetext{
" "Raybond" contributed by Raymond Company.
}

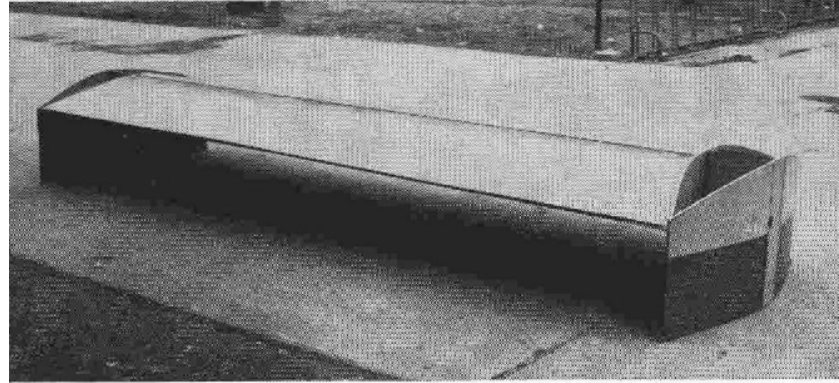

Figure 2B

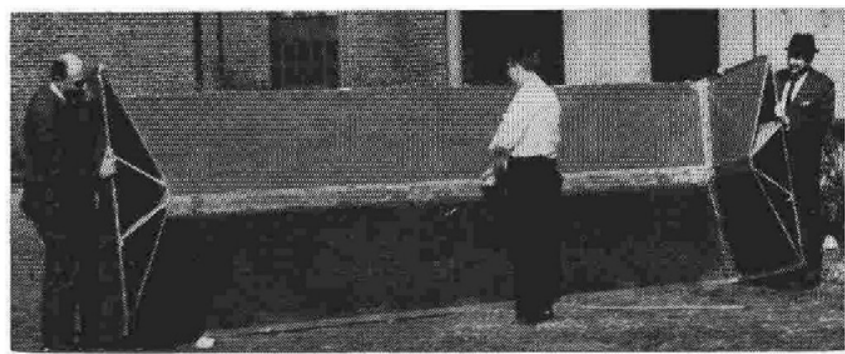

Figure 20

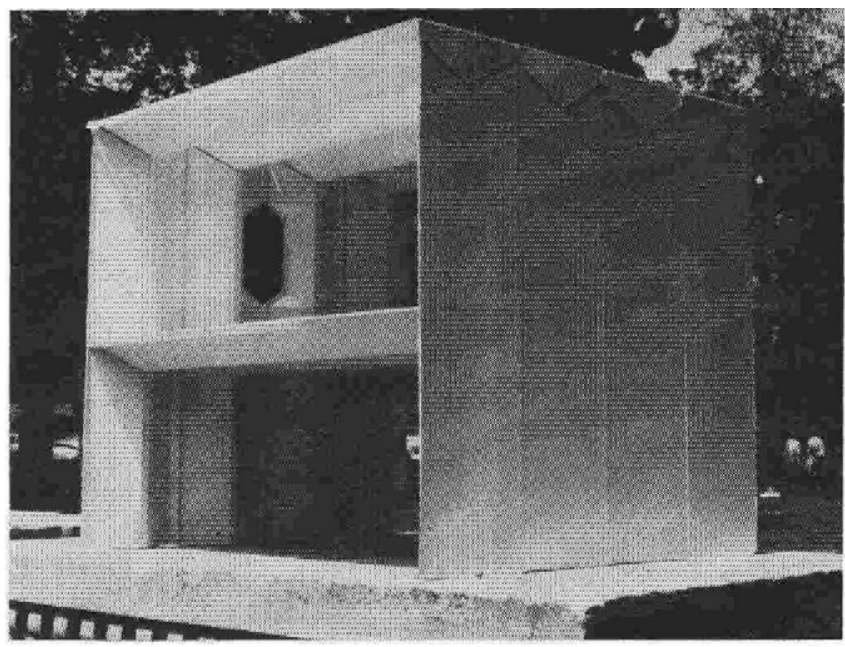

Figure 2F

tern of behavior for plastic deflection of foam and polyester paper composites. The test bent was loaded, and its deflection recorded. Assuming an allowable deflection of $1 / 240$ th of the span, the structure was found capable of carrying about 25 pounds per square foot. The internal stresses in the paper skins at this load level were found to be well within the limits of the material.

After having determined the elastic behavior of the structure, a test was then set up to find out whether there are unique characteristics in its plastic flow or creep behavior. Our objective was not only to arrive at precise conclusions which would permit prediction of design, but also to evaluate the significance of plastic flow on this particular structural cross section created from this particular material. The test bent used for this experiment was the same as that used for the elastic experiments. The structure was given a total load of 1470 pounds (18.4 P.S.F.) distributed over the surface. The 


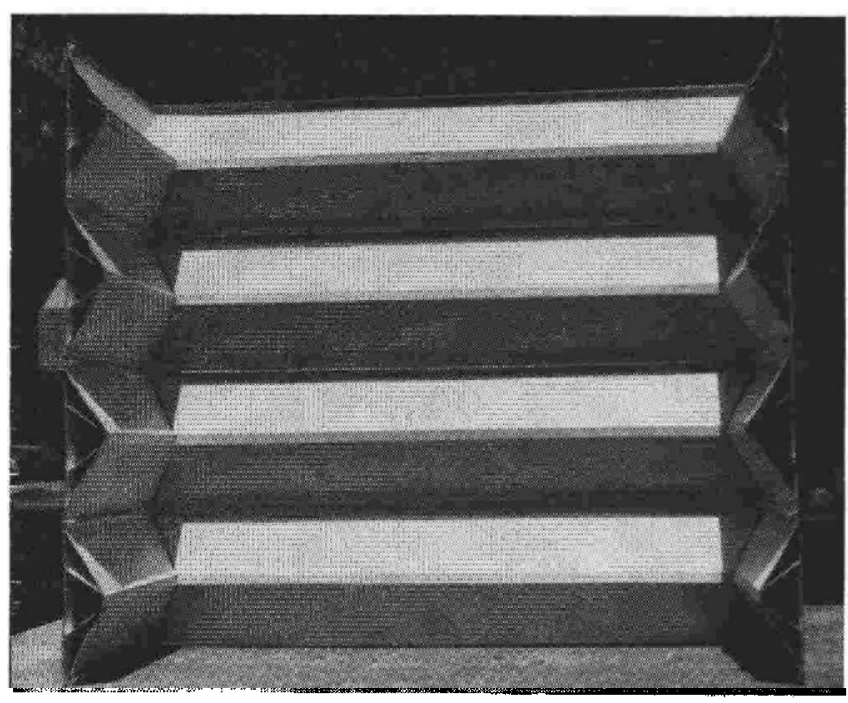

Figure 2G

load remained in place for 167 hours and was then removed. During this period readings of 10 dial gauges were recorded at a variety of intervals. Although the results of the tests are not absolutely conclusive, much of the data shows that the plot of plastic deflections against elapsed time follows a curve which seems to be leveling off.

A unique property of the structure was discovered when the loads were removed at the end of the test period. Virtually all of the elastic deflection was recovered immediately. Following this initial recovery, the structure continued to recover plastically almost all of the deformations that had accumulated over the study period. This behavior is not typical of conventional materials which, once deformed plastically, stay deformed plastically. Further investigation is needed to find out exactly what has caused this. Other experiments have been set up to explore this question and are currently in progress.

The results of this study on the test bent show that the design of substantial and durable structures utilizing paper skin urethane foam are not only feasible but relatively uncomplicated. Since the performance of the test structure was highly encouraging, we decided that a full-scale test structure should be designed and constructed.

Drawings and specifications have been completed for a 2-story test structure made up of four 4-foot bents with an 18 foot span (Figures $2 f$ and $2 \mathrm{~g})$. The necessary materials have been produced and received. At the time of writing this article we are in the process of constructing this structure at the Architectural Research Laboratory in Ann Arbor. The footings have already been poured in place and an assembly templet has been constructed for the production of the bents (Figure $2 h$ ). These bents, which are light enough to be handled by two men, will be glued together. The outer surface will be coated with pigmented polyester and the floor will be covered with an impact resistant material.

The ease with which a panel material of this nature can be scored and bent opens up new pos-

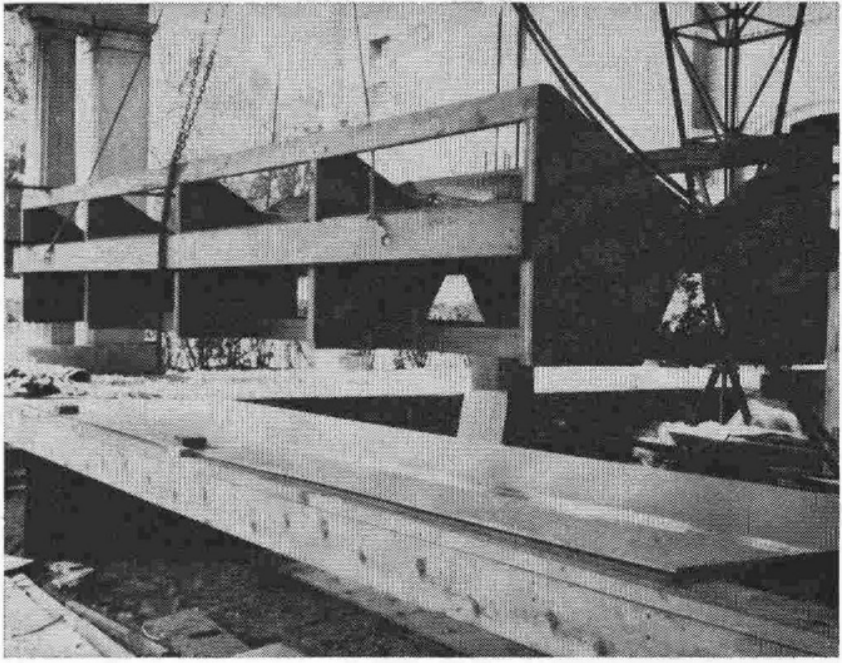

Figure 2H

sibilities for the realization of folded plate structures. From a production standpoint, the properties of urethane foam are utilized efficiently to create a sandwich panel by a continuous mechanical process which can be adjusted to meet a variety of specifications. A variety of materials obtainable in rolls may be used for the skins. However, paper seems to be one of the best suited for this purpose, because structural properties can easily be added through secondary applications depending on performance requirements within the structure.

\section{Example 3: Spray Application on a "Folding Armature" Structure}

Although some preliminary experimentation with urethane spray had made us skeptical of the practicability of spray-on techniques for the erection of structures in the field (because of the dependance on suitable environmental conditions and the difficulty of maintaining uniformity of control over the material and its appearance), it was felt nevertheless that the method merits further investigation since it is a system representative of foam plastics technology. The transportability of the system and the ease of creating varying thicknesses offer definite advantages. Besides, it is possible to control to a degree environmental factors in the field, and the other disadvantages may be overcome through skilled application, or even better, through automation of the spray process.

An essential element in a spray applcation is the "background." i.e., the formgiving surface against which the foam components are to be sprayed. After investigating various possibilities, we devised for this purpose a lightweight wood lattice armature. This armature, capable of being folded, is easily transported to a building site and quickly erected. It is made in such a way that it can be laid out flat on the ground and then pulled into a double curved structural shape.

A one-third-full-size model of the armature was first constructed in the laboratory and its behavior studied. A full-size 28-foot square armature was 


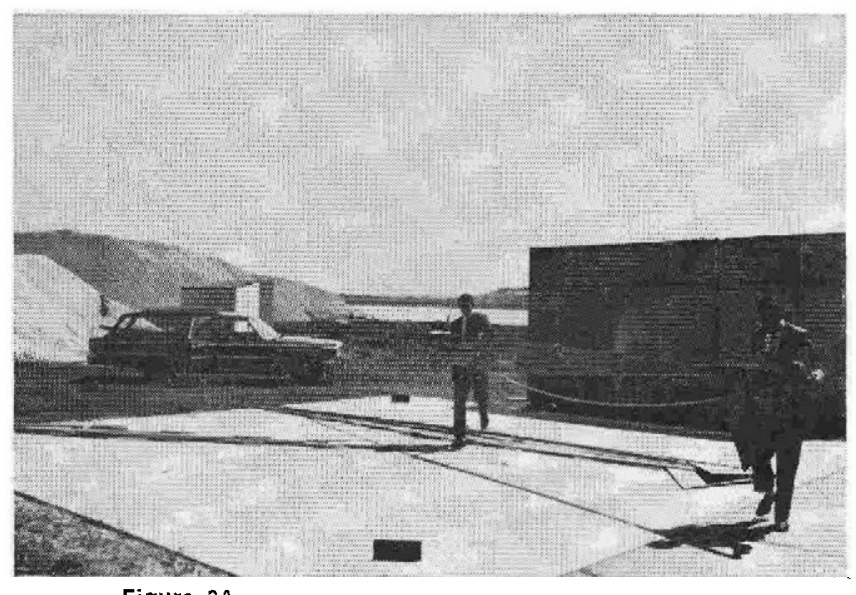

Figure $3 \mathrm{~A}$

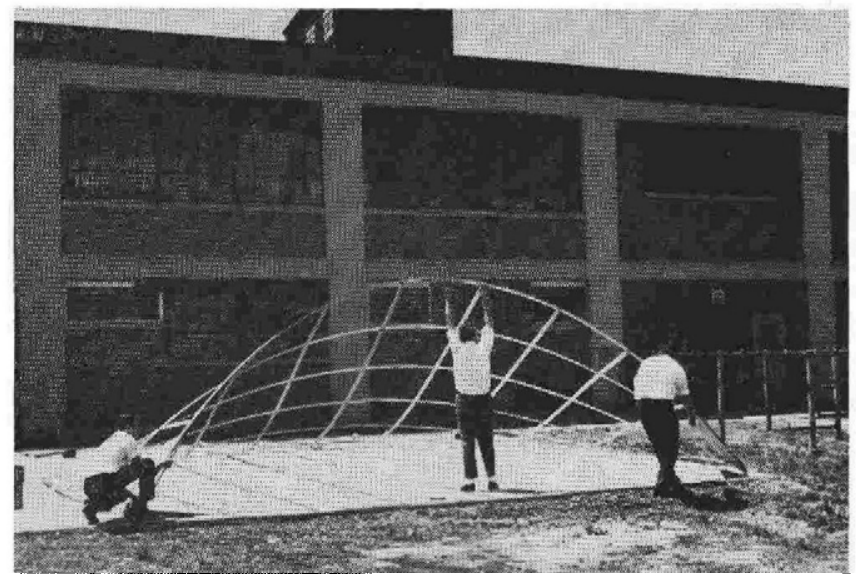

Figure 3C

then constructed which when erected into its final structural form produces approximately a 21-foot square dome structure supported on four points. This armature was erceted and taken down four times in the course of working out various problems and the technique of erection.

In May 1964 a spray structure utilizing the armature was erected in collaboration with Wyandotte Chemicals Corporation on the company's grounds. A concrete slab with appropriate anchors was prepared and construction started soon thereafter.

The folding armature was transported in four sections which were bolted together on the slab (Figures $3 a$ and $3 b$ ). Then, using tension chords, each of the 4 edge members were alternately bent into shape, and temporary tension ties were placed across each of the supporting legs of the structure to pull it into its final shape (Figures $3 c, 3 d$, and $3 e$ ). Each of the edges was then reinforced, and the entire structure covered with a stapled-on nylonreinforced paper skin* (Figures $3 f$ and $3 g$ ). One-half of the surface was sprayed for experimental purposes with a moisture-curing urethane resin * (Figure $3 h$ ). The foam was then sprayed on the structure (Figures 3i, 3i, and $3 k$ ). The density of the foam was close to $2 \frac{1}{2}$ pounds a cubic foot, and some 700 pounds of foam were used to produce a structure approximately 4 inches thick. It

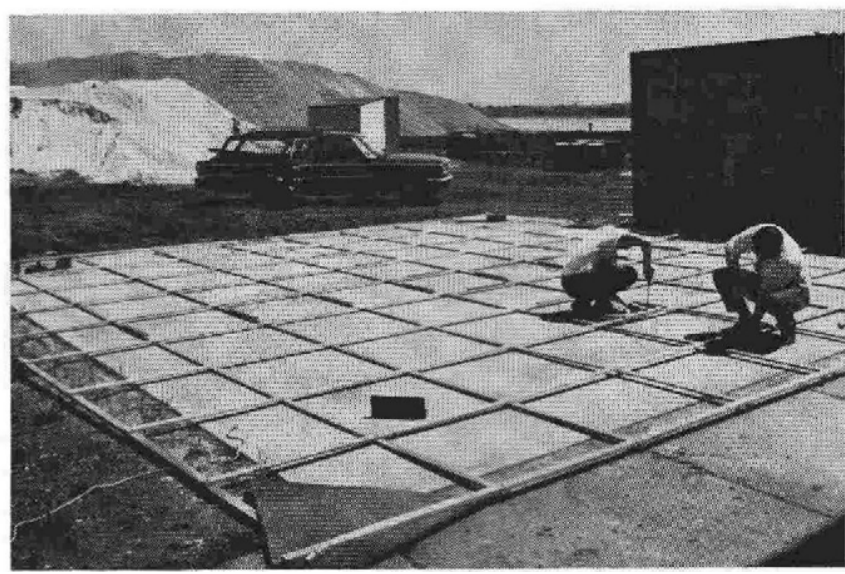

Figure 3B

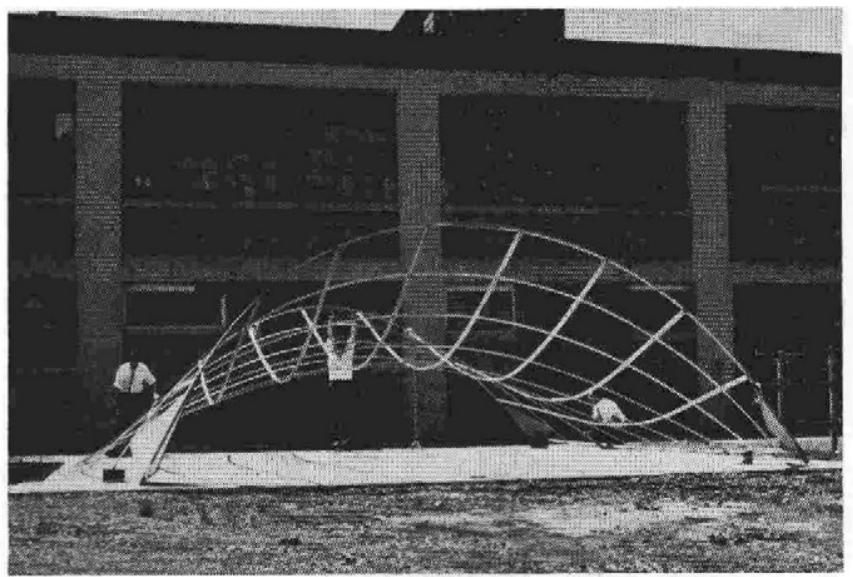

Figure 30

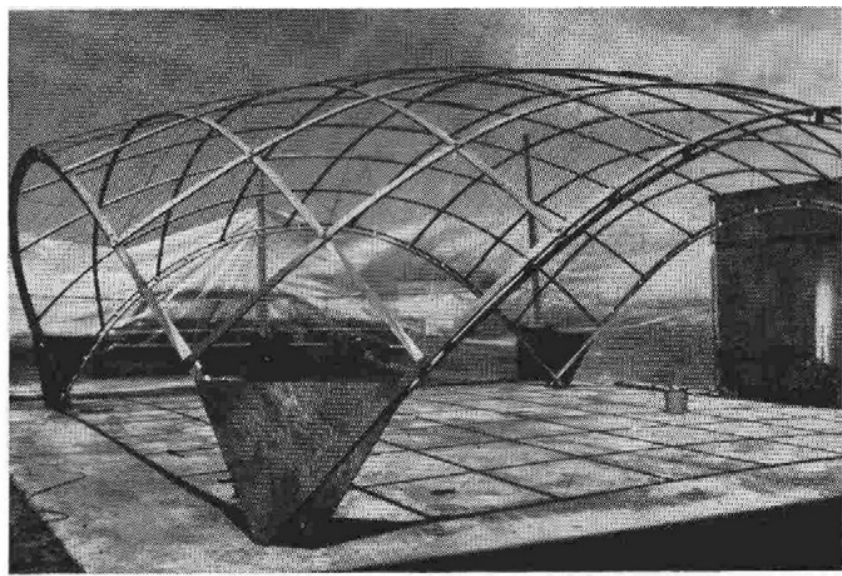

Figure $3 \mathrm{E}$

took almost 8 man-hours to complete the spraying. The surface appearance of the structure was quite good and much more acceptable than in our initial experiments (Figure 31.)

Our original approach to the design of the structure had been to consider the wood armature only as a formwork on which the foam was to be

\footnotetext{
" "Kaycell," contributed by Kimberly Clark Company - Developed by Wyandotte

9 A Binks Model 18FM spray gun was used
} 


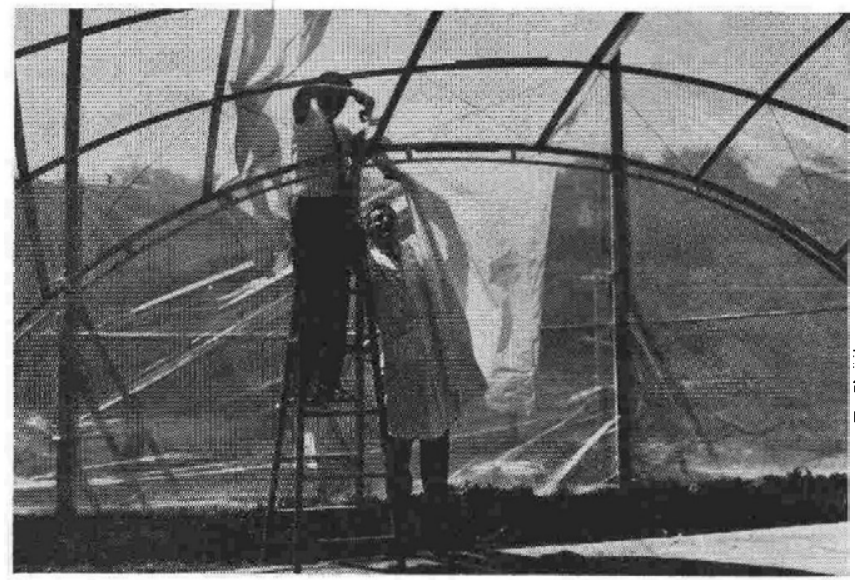

Figure 3F

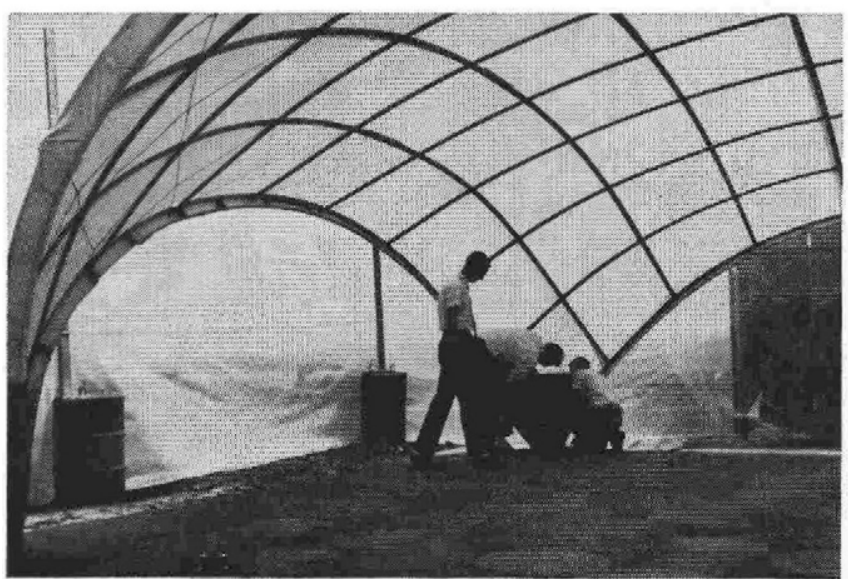

Figure 3G sprayed. Model studies indicated that the armature was not capable of taking the total weight of the foam and therefore the sequence of the spraying operation became an important consideration in the construction of the structure. First the buttress portion and then the peripheral section were sprayed. Thus the foam began working structually as the armature was being sprayed. There were several unexpected problems, some of which resulted from design considerations and others from the construction methods. First, the dead load of the foaming caused an initial distortion in the structure which had not been anticipated. Secondly, inadequate edge stiffnesses caused higher stress levels in the buttress portions of the shell than were anticipated. This was probably due to the fact that the edge members were not foamed to the final thickness prior to foaming the rest of the shell.

Measurements were made of the structure two weeks after the foaming had been completed. At

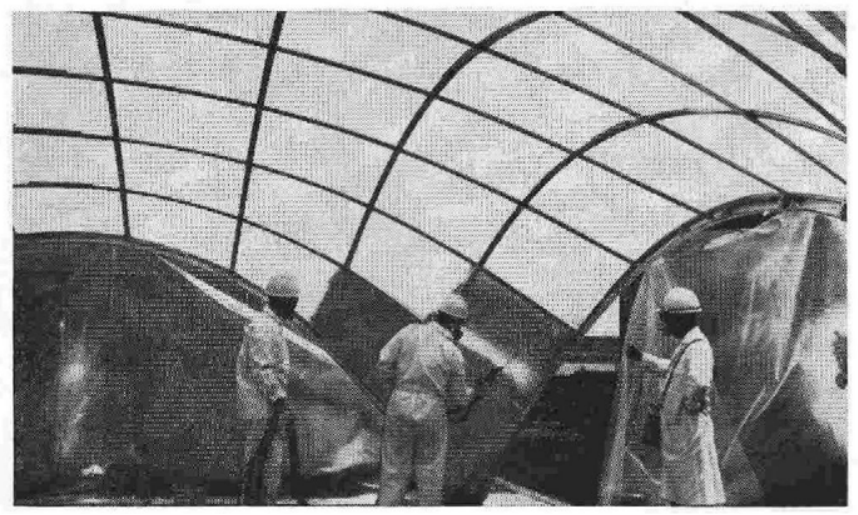

Figure 31

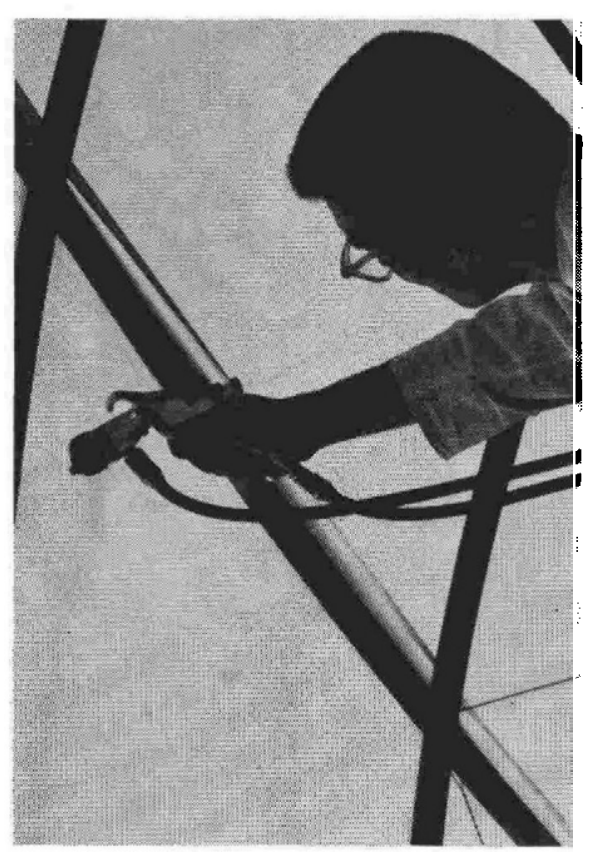

this time there seemed to be noticeable movements, particularly in the buttress section. Three weeks later the structure was measured again. At this time there was considerable movement, particularly at the top of the edge support which had come down approximately six inches. It was noted also that the shape of the curve of the edge member had changed considerably, becoming much flatter.

During the three-week period between the first and second measurements, a small but accurate wire model of the armature was constructed and carefully tested in an attempt to predict more precisely the nature of the behavior of the structure. From the study of this small test model we were able to see that the primary failure of the structure would occur in the buttress section and if the edge member was adequately stiffened, a secondary failure would occur due to buckling of the domical portion

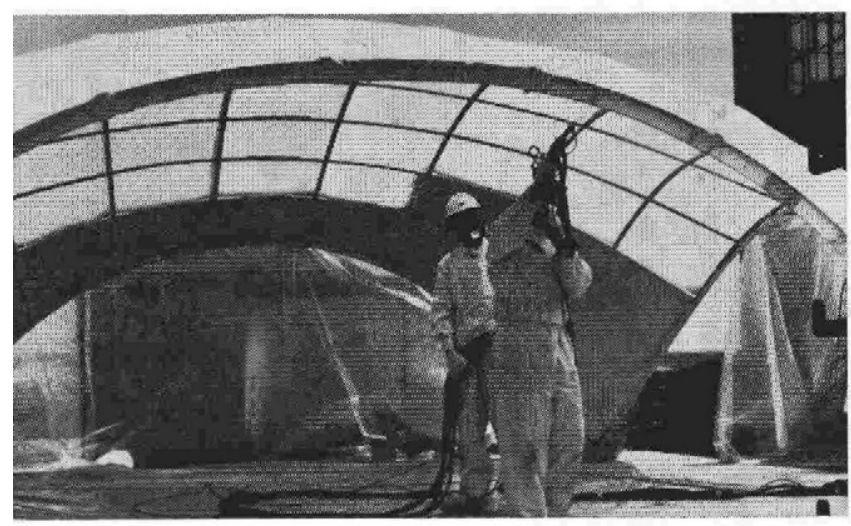

Figure 3 3 


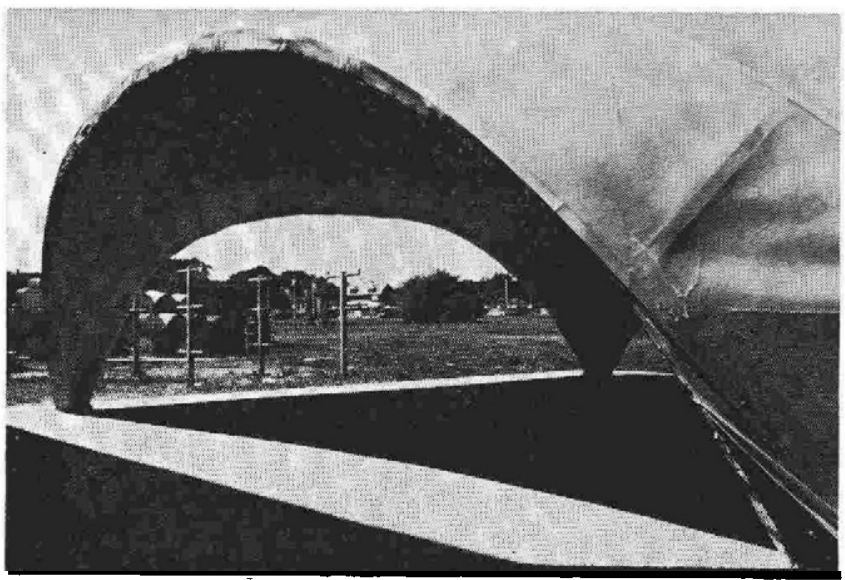

Figure 3K

of the shell. Also, during this period several tests were run on samples of the urethane foam which had been sprayed on the dome. These tests were run in hopes of finding the cause of the slow deformation of the structure under its own weight,

Compression, flexural, shear, and creep studies were also conducted. It was found that the material had a considerable higher strength parallel to the direction of rise. Compression strength perpendicular to the direction rise was approximately 20 lbs. per square inch and the compressive strength parallel to the direction rise was more than $40 \mathrm{lbs}$. per square inch. Creep studies revealed that even at rclatively low stress levels plastic deformations continued for considerable time without reaching a plateau. These creep characteristics became a particular problem in the higher stressed buttress portion of the dome where they caused successive increase in deformations and stress levels.

We therefore decided to put the structure back into its original shape and reinforce the edge members so that the stress levels in the foam would be lowered. This was done in the belief that the lower stress levels in the structure would produce acceptable levels of plastic deformations over a long period of time. Further measurements and tests will continue throughout the summer.

This first experimental structure has demonstrated the feasibility of using spray foam tech-

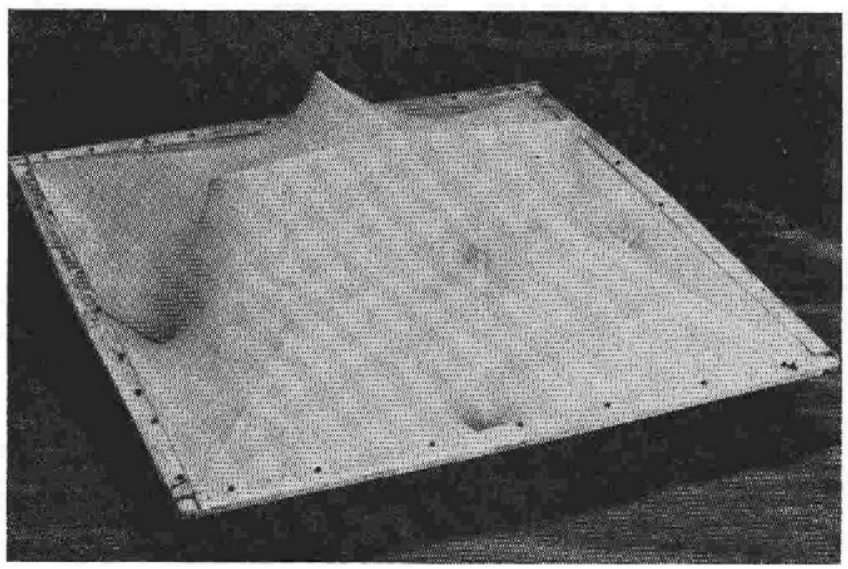

Figure 4A

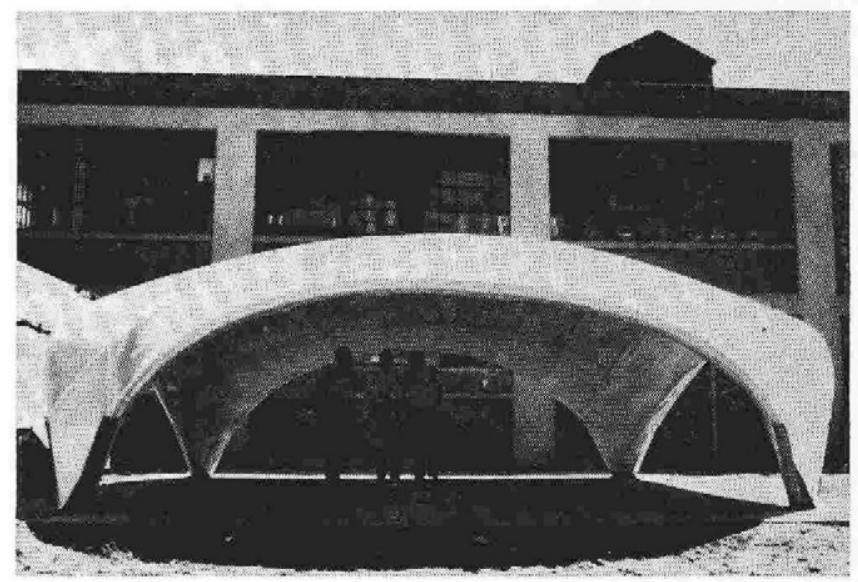

Figure 3L

nology in the field for easily erected structural units. With the information obtained from the tests of the first structure and additional model tests on the armature, we feel confident that a second test structure which will be built in the fall will be free from the defects of the first. In the proposed second structure we anticipate that the stronger edge member in combination with a major tension tie within the armature will reduce stress concentrations. We also anticipate the use of a higher density foam formulation which should produce acceptable levels of long term deformations. Much work needs to be done on the nature of creep properties of foam plastics in general.

\section{Example 4: Structure Made by Rigidizing Flexible Urethane Foam}

One of the structural concepts under consideration has been the possibility of erecting doublecurved surfaces by rigidizing flexible membranes after they have been stretched to the desired shape. Several experiments were conducted at small model scale using such materials as nylon jersey and glass cloth in combination with epoxy, polyester, and urethane resins (Figure 4a).

This idea was translated into flexible foams, but there appeared to be too many difficulties involved in producing sizable components by impregnating them after they had been shaped. When Wyan-

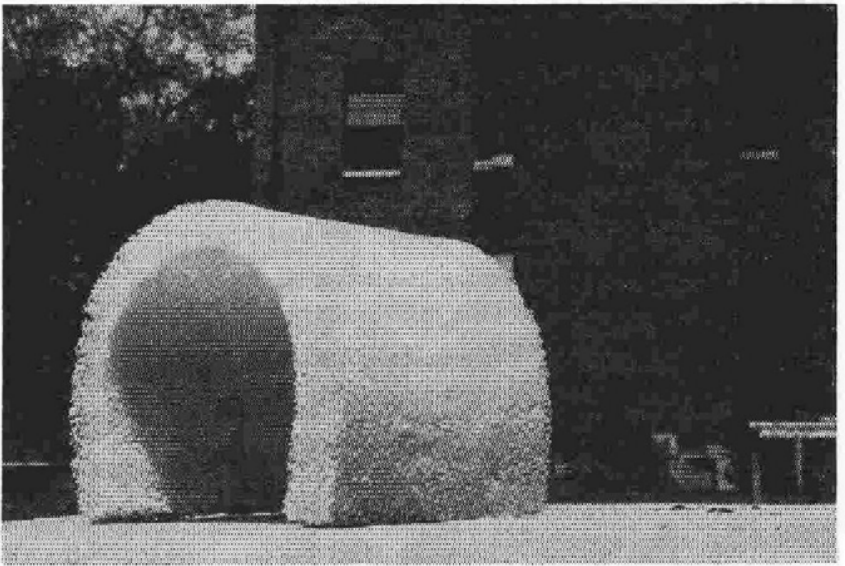

Figure 4B 


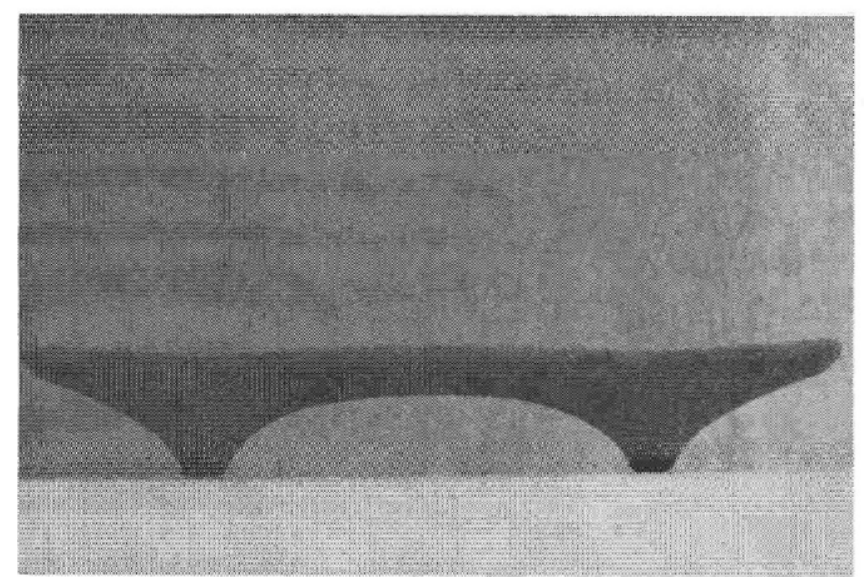

Figure 4C

dotte presented us with the moisture-curing urethane resin mentioned in the previous example, the thought occurred that the flexible components might be pre-impregnated. This brought the concept closer to the realm of feasibility, Thus we could envision the possibility that component parts of a structure might even be pre-impregnated under controlled environmental conditions, sealed into a moisture-free bag and stored until needed. At that time, they would be pulled out, erected into final shapes, and allowed to cure by atmospheric moisture.

After some searching to find a proper material for rigidization we decided on a reticulated flexible urethane foam having a fairly large cell structure."

Small samples were prepared by impregnating this foam with the moisture-curing resin, removing the excess resin, and allowing it to cure (Figure $4 b$ ). Since this impregnation technique offered little technical difficulty, we decided to build a full-scale test structure. The material at hand served to produce two identical structural components. This was done by clamping a sheet of this foam ( $4 \times 16$ feet, 1 inch thick) in a wooden frame, and then pulling down two points to produce a warped structural component (Figures $4 c$ and $4 d$ ).

As this paper is being prepared, arrangements are being made to spray both surfaces with chopped fiberglass and polyester resin. We intend to erect a test structure outside the Architectural Research Laboratory by joining the two structural components and supporting them on four tubular columns. Although it is still in the very early stage of development we feel that this process holds fruitful potentials for the future.

\section{Summary}

Our program of research explores various possibilities for utilizing cellular plastics as structural materials in their own right rather than as substitutes for other materials. Questions to be answered are: What new structural solutions become possible through their logical use and application? How can these solutions best contribute towards the resolution of the housing problem in

"Scottfoam" contributed by the Scott Paper Company.

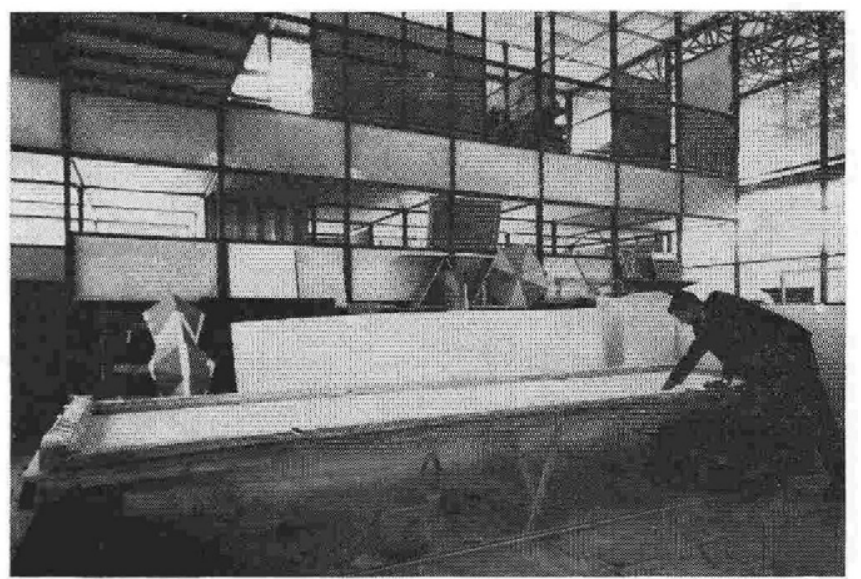

Figure 4D

the underdeveloped areas of the world? Maybe the best is still not good enough, but in an age of chemistry it seems worthwhile to find out.

\section{Acknowledgments}

This research is being conducted with my colleagues; Harold J. Borkin, J. Sterling Crandall, Robert M. Darvas, James L. Haecker, C. Theodore Larson, and Willard A. Oberdick. In addition to the companies already mentioned in the text and whose collaboration has made this work possible, we should like to express our sincere appreciation to Atlas Chemical Industries, E. I. du Pont de Nemours and Company, Mobay Company, and Pyles Industries for their assistance during this beginning phase of our project, as well as to the entire plastics industry for the information and the resources made available to us.

\section{References}

1. "The Potential Use of Foam Plastics for Housing in Underdeveloped Areas," Architectural Research Laboratory, The University of Michigan, Anu Arbor, March 1963.

\section{Stephen C. A. Paraskevopoulos}

Prof. Stephen Parsakevopoulos was born in Athens, Greece on May 21,1926 . He became a U.S. citizen in May 1963.

He was graduated from the $\mathrm{Na}$ tional Technical University of Athens in 1951 with a Dipl. Ing. degree; and he received a $M$. Arch. from The University of Michigan in 1954.

His professional background in-

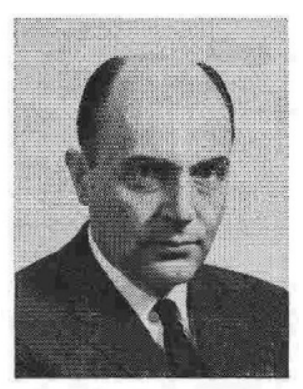
cludes architectural practice and building studies in Athens, Greece and Ann Arbor, Michigan, consultant on social and economic aspects of housing and resident architect in Indonesia for the United Nations, and architectural hospital consultant at The University of Michigan.

From 1955-1956 he was a visiting lecturer at the University of Michigan; from 1956-1960 he was an assistant professor; from 1960-64 he was an associate professor and he is currently a professor, Dept. of Architecture, The University of Michigan.

He has participated in the University's research programs: "Unistrut Space-Frame System" and "School Environments Research" directed by Prof. C. T. Larson; and is directing the project on "Foam Plastics for Housing in Underdeveloped Areas." 